\title{
The Effect of Single-Dose Preemptive Intravenous Ibuprofen on the Intraoperative Hemodynamic Parameters, Recovery Characteristics, and Acute Pain after Laparoscopic Cholecystectomy: A Randomized Double-Blind, Placebo-Controlled Clinical Trial
}

\author{
Ozlem Sezen, MD* (D), Banu Cevik (D, MD and Kemal Tolga Saracoglu (D, MD \\ University of Health Sciences, Kartal Dr.Lutfi Kırdar Training and Research Hospital, Turkey
}

*Corresponding author: Ozlem Sezen, MD, University of Health Sciences, Kartal Dr. Lutfi Kırdar Training and Research Hospital, Istanbul, Turkey, Tel: 90216-441-39-00; +90532-391-82-98

\begin{abstract}
Background/aims: The aim of this study was to investigate the effects of the preemptive administration of a single dose of intravenous (IV) ibuprofen on the intraoperative hemodynamic parameters, recovery characteristics, and postoperative pain management in patients undergoing laparoscopic cholecystectomy. The time to first analgesic requirement during postoperative period was the main goal of this study.

Material and methods: Following ethical committee approval, sixty patients scheduled for laparoscopic cholecystectomy with American Society of Anesthesiologists (ASA) physical status I-II and aged 30-65 years of either genders were included in this prospective, randomized, placebo-controlled double blinded study. Patients were randomly divided into two groups.

The study group (group I) received $400 \mathrm{mg}$ ibuprofen in 100 $\mathrm{ml}$ IV saline 15 min before anesthesia induction, whereas the placebo group (group C) received IV $100 \mathrm{ml}$ saline only. The study drug and the saline were administered by an anesthesia nurse blinded to the study. The same general anesthesia protocol was applied in both groups. Hemodynamic parameters (non-invasive systolic (SAP), diastolic (DAP) and mean (MAP) arterial pressure, heart rate (HR), bispectral index (BIS) values and $\mathrm{SpO} 2$ values were recorded before induction (baseline) and after induction, peroperative $10,20,30$, minutes., before extubation. The time to achieve a modified Aldrete score of $\geq 9$ was recorded as the recovery time. During postoperative period, the time to first analgesic requirement and the total amount of analgesics within 24 hours was recorded. Patients were asked to give a number between from 1 to 5 for the satisfaction assessment for the anesthesia management.
\end{abstract}

\begin{abstract}
Results: There was no difference between the groups in terms of hemodynamic findings before anesthesia induction and in the peroperative period. The time until Aldrete score of 9 was statistically significantly shorter in Group I (Group I $3.8 \pm 1.4 \mathrm{~min}$, and Group C $6.3 \pm 1.9 \mathrm{~min}, \mathrm{p}<0.001$ ). Sevoflurane consumption was lower in the group given preemptive single dose IV ibuprofen, but the time to first postoperative analgesic requirement was longer $(p<0.001)$. Total analgesic consumption was highest in Group $C(p<$ 0.001).

Conclusion: Preemptive single dose i.v. ibuprofen (400 $\mathrm{mg}$ ) can be used in laparoscopic cholecystectomy with the advantages of reducing the consumption of peroperative sevoflurane, providing better VAS scores, shortening the time to the first postoperative analgesic requirement and reducing analgesic consumption.
\end{abstract}

\section{Keywords}

Ibuprofen, Preemptive analgesia, Laparoscopic cholecystectomy, Postoperative analgesia

\section{Introduction}

Laparoscopic cholecystectomy is a widely preferred minimally invasive surgical technique for gallstone diseases due to its shorter hospitalization, faster healing, a better cosmetic outcome, and less postoperative pain characteristics. The pain after laparoscopic cholecystectomy is regarded as visceral, quite complex and resulted from the insufflation of carbon dioxide into the peritoneal cavity, abdominal distension, port-site incisions

Citation: Sezen O, Cevik B, Saracoglu KT (2020) The Effect of Single-Dose Preemptive Intravenous Ibuprofen on the Intraoperative Hemodynamic Parameters, Recovery Characteristics, and Acute Pain after Laparoscopic Cholecystectomy: A Randomized Double-Blind, Placebo-Controlled Clinical Trial. Int J Anesthetic Anesthesiol 7:118. doi.org/10.23937/2377-4630/1410118

Accepted: December 29, 2020: Published: December 31, 2020

Copyright: (c) 2020 Sezen O, et al. This is an open-access article distributed under the terms of the Creative Commons Attribution License, which permits unrestricted use, distribution, and reproduction in any medium, provided the original author and source are credited. 
and patient factors [1]. Although the pain intensity and duration are less than the open surgical approach, the optimum analgesic modality has remained a challenging issue. Multimodal analgesia regimen combining opioids, non-steroidal anti-inflammatory drugs, and local anesthetic infiltration to the port sites are the most recommended treatment of choices for postoperative pain management after laparoscopic cholecystectomy [2].

Preemptive use of systemic analgesics combined with the general anesthesia has some beneficial effects such as blocking nociceptive pathways, reducing the amount of pharmacological agents needed to maintain the general anesthesia, and decreasing the time to recover from the drug-induced central nervous system depression [3]. Adequate preemptive analgesia has two basic requirements; verification of the effectiveness of the direct pharmacological effect of treatment and the extension of an antinociceptive treatment into the initial postoperative period [4].

Nonsteroidal anti-inflammatory drugs (NSAIDs) are the good treatment of choices for the postoperative pain unless contraindicated due to its opioid-sparing effect and minimizing the opiate-induced adverse reactions [5]. The guideline of the American Society of Anaesthesiologist, Task Force on Acute Pain Management recommends that this group of drugs have a significant role in postoperative multimodal pain management [6].

Like other NSAIDs, ibuprofen has anti-inflammatory, antipyretic, and analgesic properties. It causes a rapid, reversible and competitive inhibition of the cyclooxygenase (COX) isoenzymes. The analgesic property is related to the inhibition of COX-2, whereas the inhibition of COX-1 isoenzyme results in the gastrointestinal or kidney side effects [7]. This drug is a propionic acid derivative and the oral form has been widely used for many years. By the introduction of ready-to-administration intravenous ibuprofen solution, it's increasingly been used in multimodal analgesia for the management of postoperative pain [8]. It's been shown that the use of intravenous (IV) ibuprofen is a safe and effective drug to reduce the severity of pain, and opioid consumption in surgical interventions such as bariatric, orthopedic, abdominal, and gynecologic surgeries [9-12]. The effect of NSAIDs on wound healing is a debating issue and animal studies indicated that non-selective NSAIDs generally inhibit wound healing. However, either COX1 or COX-2 selective NSAIDs tend to show no effect on wound healing [13].

The aim of this study was to investigate the effects of the preemptive administration of a single dose of IV ibuprofen on the intraoperative hemodynamic parameters, recovery characteristics, and postoperative pain management. The time to first analgesic requirement during postoperative period was the main goal of this study.

\section{Materials and Methods}

This prospective, randomized, placebo-controlled double blinded study was conducted after receiving the approval of the ethics committee (2020/514/170/24) and the written, informed consent of all of the participants, according to the Good Clinical Practice guidelines and the principles of the Declaration of Helsinki. Sixty patients scheduled for laparoscopic cholecystectomy with American Society of Anesthesiologists (ASA) physical status I-II and aged 30-65 years of either genders were included the study.

\section{Exclusion criteria}

Patients with a body mass index of more than $30 \mathrm{~kg} /$ $\mathrm{m}^{2}$, pregnancy, cardiac or renal failure, mental disturbance, neurological disease, communication difficulties, being unable to comprehend visual analogue scale, previous clinical history of chronic pain, a history of longterm or during recent $24 \mathrm{~h}$ nonsteroidal anti-inflammatory drug use, a history of peptic ulcer, gastrointestinal bleeding or inflammatory bowel disease, known allergy to ibuprofen or other nonsteroidal anti-inflammatory drugs were excluded.

Randomization was achieved by using a computer-generated randomization program operated by another clinician blinded to the study and the patients were allocated into two groups to receive either preemptive single dose IV ibuprofen (Intrafen $400 \mathrm{mg} / 4 \mathrm{ml}$, en İlaç Ve Sağlık Ürünleri San. Ve Tic. Ltd. Sti., Ankara, Türkiye) (Group I $=30)$ or IV saline $(100 \mathrm{ml}$ ) (Group C = 30).

\section{Anesthesia procedure}

Patients were interviewed preoperatively to explain the study and introduced to the concept of the visual analog scale (VAS), with a $10-\mathrm{cm}$ vertical score ranged from $0=$ no pain to $10=$ worst pain imaginable. The patients fasted for both solids and clear liquids at least 8 hours prior to the surgical procedure. No premedication was applied.

On arrival to the preoperative care unit, IV access was established with an 18-G IV cannula. The study group received $400 \mathrm{mg}$ ibuprofen in $100 \mathrm{ml}$ IV saline 15 min before anesthesia induction, whereas the placebo group received IV $100 \mathrm{ml}$ saline only. The study drug and the saline were administered by an anesthesia nurse blinded to the study.

Before induction of anesthesia, a bispectral index sensor (BIS Quatro; Medtronic plc, Dublin, Republic of Ireland) was placed on the patient's forehead and connected to a BIS Vista monitor (Medtronic plc, Dublin, Republic of Ireland). Following standard monitoring included a 3-lead electrocardiogram (ECG) with continuous ST-segment analysis, peripheral oxygen saturation $\left(\mathrm{SpO}_{2}\right)$, and non-invasive blood pressure, anesthesia in 
both groups was established with IV $1 \mu \mathrm{g} / \mathrm{kg}$ fentanyl and $2-2.5 \mathrm{mg} / \mathrm{kg}$ propofol. Endotracheal intubation was facilitated by the administration of IV rocuronium 0.6 $\mathrm{mg} / \mathrm{kg}$. Anesthesia was maintained with sevoflurane of $2-3 \%$ in $50 \%$ oxygen-air mixture in a fresh gas flow of 2 L/minute.

Hemodynamic goals were to maintain the intraoperative mean arterial pressure and heart rate within $20 \%$ of the pre-induction values. If the mean arterial pressure and heart rate increased more than $20 \%$, supplementary dose of $1 \mu \mathrm{cg} / \mathrm{kg}$ fentanil was applied. In case of decreasing more than $20 \%, 5 \mathrm{mg}$ IV ephedrine was administered. Sevoflurane was titrated to maintain a BIS value between 40 and 60 .

\section{Surgical procedure}

Laparoscopic cholecystectomy was performed with four-port standard technique by highly experienced surgeons in laparoscopic interventions. After insertion of a subumblical $10-\mathrm{mm}$ port, pneumoperitoneum was created by placing a Veress needle and the intraabdominal pressure was maintained at $10-12 \mathrm{mmHg}$. The operation table was positioned in reverse Trendelenburg and sided to the left. A 10-mm trocar was placed in the epigastrium to the right of the falciform ligament with two additional 5-mm ports in the right upper abdomen. After resection of gallbladder, it was retrieved through the epigastric port. Nasogastric tube was used only for decompression of the stomach and then removed. No abdominal drainage was used to any patient.

At the end of the surgery, the anesthetic gas mixture was replaced with $100 \%$ oxygen and the neuromuscular block was reversed using a neostigmine $(0.05 \mathrm{mg} / \mathrm{kg})$ and atropine $(0.01 \mathrm{mg} / \mathrm{kg})$ combination. After adequate ventilation, protective airway reflexes and the patients' response to verbal commands were achieved, patients were extubated. Following transfer to the post-anesthesia care unit, they discharged to the general surgery clinic when patients attained a modified Aldrete score of $\geq 9$.

\section{Data collection}

Patient characteristics of age, gender, height, weight, and ASA physical status were recorded. Hemodynamic parameters (non-invasive systolic (SAP), diastolic (DAP) and mean (MAP) arterial pressure, heart rate (HR), bispectral index (BIS) values and $\mathrm{SpO}_{2}$ values were recorded before induction (baseline) and after induction, peroperative $10,20,30$, minutes, before extubation.

The time to achieve a modified Aldrete score of $\geq 9$ was recorded as the recovery time. During postoperative period, the time to first analgesic requirement and the total amount of analgesics within 24 hours was recorded. Patients were asked to give a number between from 1 to 5 for the satisfaction assessment for the anesthesia management.

\section{Statistical analysis}

The demographic characteristics and collected data of the patients were entered into IBM ${ }^{\circledR}$ SPSS $^{\circledR}$ (the Statistical Package for the Social Sciences) Statistics version 23. Variables were characterized using mean, maximum and minimum values, and percentage values were used for qualitative variables. Normal distributions were reported as mean \pm SD and Student's t-test was used for comparisons between groups. For the analysis of qualitative variables Pearson chi-square test was used if the group was small, Fisher's exact test was used. Nonparametric continuous variables were recorded as median and intermittent distribution and compared using Mann-Whitney $U$ tests. In the comparison of both groups in terms of VAS, two-way ANOVA test was used for the change in time. $p<0.05$ value was considered statistically significant.

\section{Results}

Totally 60 patients were recruited into the study (Figure 1). Patients' characteristics were shown in Table 1.

There was no difference between the groups in terms of hemodynamic findings before anesthesia induction and in the peroperative period. However, BIS values were found to be higher in Group I from the $20^{\text {th }}$ minute to the pre-extubation period compared to Group $\mathrm{C}$ and were statistically significant in this regard (Table 2).

Aldrete 0 minute scores were similar between groups (7.4 \pm 0.5 in Group I, and 7.2 \pm 0.5 in Group C, $p=$ 0.139). Aldrete $1^{\text {st }}$ hour scores were 9 in all patients. The time until Aldrete score of 9 was statistically significantly shorter in Group I (Group I $3.8 \pm 1.4$ min, and Group C $6.3 \pm 1.9 \min , p<0.001$ ).

Sevoflurane consumption was lower in the group given preemptive single dose IV ibuprofen, but the time to first postoperative analgesic requirement was longer (Table 3). When the total amount of analgesics used in the first postoperative 24 hours was compared, only $1 \mathrm{~g}$ i.v. paracetamol was sufficient for all patients in Group $\mathrm{I}$, whereas the control group required $1.7 \pm 0.7 \mathrm{~g}$ i.v. paracetamol $(p<0.001)$. In addition, $100 \mathrm{mg}$ i.v. tramadol was administered to all patients in the control group as an additional analgesic.

When both groups were compared in terms of VAS scores, patients who were given preemptive single dose i.v. ibuprofen had significantly lower VAS scores (Table 4).

Nausea and/or vomiting was not observed in any patient.

\section{Discussion}

The aim of this study was to evaluate the effect of postoperative analgesic effectiveness of preemptive ibuprofen on peroperative hemodynamic parameters and recovery criteria in laparoscopic cholecystectomy. 


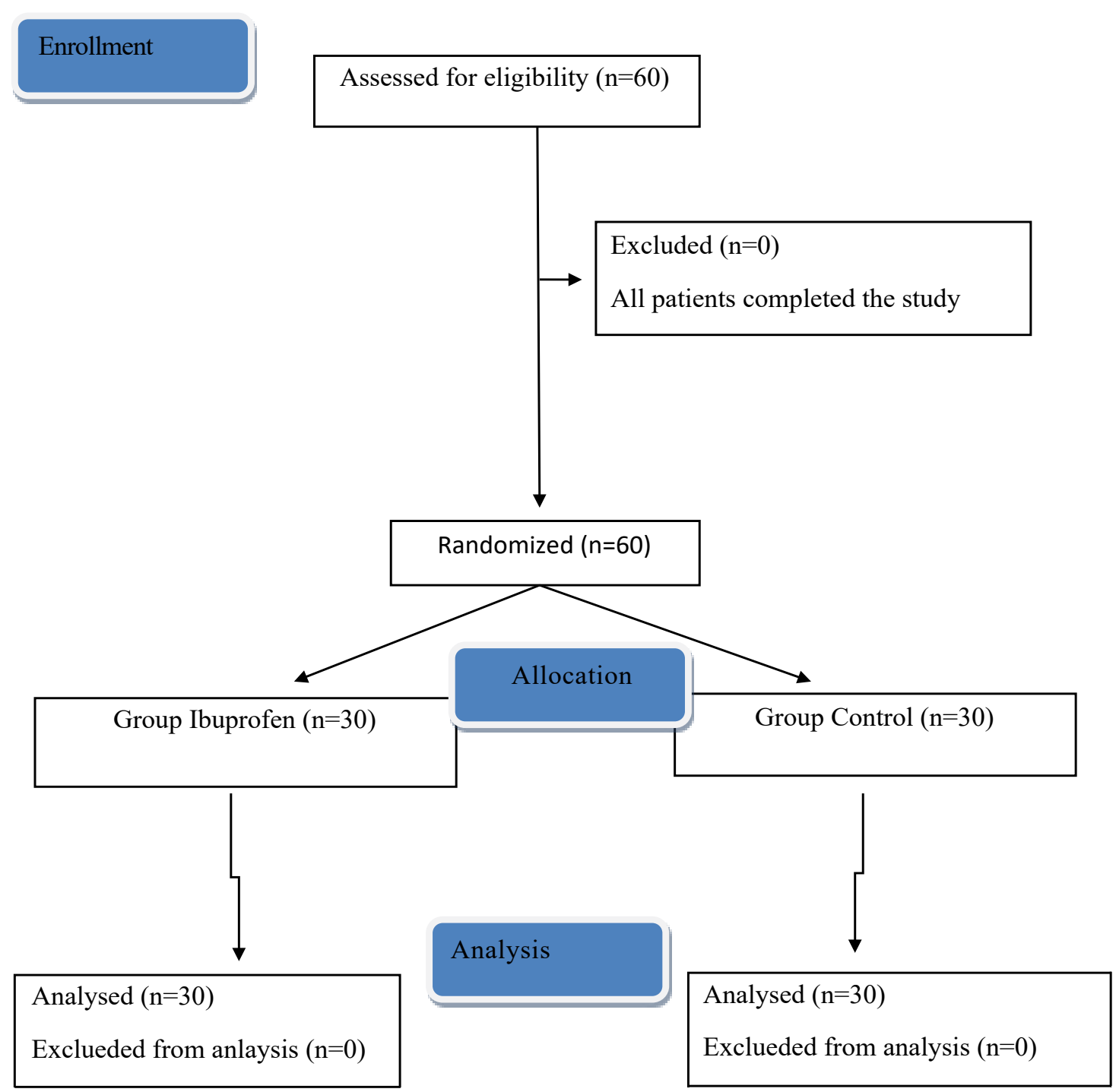

Figure 1: The CONSORT flowchart of the study.

Table 1: Patients characteristics.

\begin{tabular}{|l|l|l|l|}
\hline Variables & Group I & Group C & P value \\
\hline Age $($ years) & (15.5 & $42.6 \pm 9.6$ & 0.208 \\
\hline Gender & & & 1.000 \\
\hline Female & $16(26.7 \%)$ & $16(26.7 \%)$ & \\
\hline Male & $14(23.3 \%)$ & $14(23.3 \%)$ & \\
\hline Weight $(\mathrm{kg})^{1}$ & $77.2 \pm 14.0$ & $71.2 \pm 10.2$ & 0.053 \\
\hline Height $(\mathrm{cm})^{1}$ & $166.0 \pm 8.4$ & $167.5 \pm 7.5$ & 0.427 \\
\hline ASA physical status ${ }^{2}$ //II & $10 / 20$ & $16 / 14$ & 0.118 \\
\hline
\end{tabular}

Data was expressed as ${ }^{1}$ Mean \pm Standard Deviation (SD); ${ }^{2}$ The number of patients $(\mathrm{n})$ and the percentage (\%). ASA: American Society of Anesthesiologist' kg: Kilograms; cm: Centimeters

As a result of the study, it was observed that the pre-operative ibuprofen decreased peroperative sevoflurane consumption, the time to first analgesic requirement. Besides, the time to recovery was shorter, and there was a statistically significant decrease in VAS scores compared to the control group. Also in the group given ibuprofen, analgesic consumption was found to be less in the postoperative period.

In the postoperative period, patients complain of severe pain c after laparoscopic cholecystectomy [14]. For this reason, many analgesic drugs are applied to patients before, during or after surgery [15]. An effective postoperative analgesia results in early mobilization, shortened hospital stay, and reduced costs. One method for postoperative pain management is preemptive analgesia. This method represents analgesic administration before painful stimulation begins [16]. Local anesthetics such as bupivacaine, lidocaine and drugs such as ibuprofen, gabapentin, pregabalin can be used [17]. 
Table 2: Hemodynamic parameters of the patients (mean \pm SD).

\begin{tabular}{|c|c|c|c|}
\hline & Group I & Group C & $p$ \\
\hline $\begin{array}{l}\text { Preoperative } \\
\text { SAB (mmHg) } \\
\text { DAB (mmHg) } \\
\text { MAP (mmHg) } \\
\mathrm{HR} \text { (beats/minute) } \\
\mathrm{SpO}_{2} \% \\
\mathrm{BIS}^{\circ}\end{array}$ & $\begin{array}{l}142.3 \pm 14.8 \\
84.5 \pm 7.7 \\
107.0 \pm 10.4 \\
83.7 \pm 10.4 \\
99.1 \pm 0.8 \\
96.6 \pm 2.3\end{array}$ & $\begin{array}{l}140.5 \pm 14.0 \\
82.3 \pm 9.2 \\
106.4 \pm 14.2 \\
84.5 \pm 12.6 \\
99.4 \pm 0.8 \\
97.2 \pm 1.4\end{array}$ & $\begin{array}{l}0.589 \\
0.304 \\
0.525 \\
0.734 \\
0.072 \\
0.388\end{array}$ \\
\hline $\begin{array}{l}\text { After induction } \\
\mathrm{SAB} \\
\mathrm{DAB} \\
\mathrm{MAP} \\
\mathrm{HR} \\
\mathrm{SpO}_{2} \\
\mathrm{BIS}\end{array}$ & $\begin{array}{l}124.5 \pm 24.5 \\
76.0 \pm 18.1 \\
94.4 \pm 18.8 \\
87.0 \pm 13.7 \\
99.6 \pm 0.7 \\
33.2 \pm 9.2\end{array}$ & $\begin{array}{l}125.2 \pm 20.0 \\
74.5 \pm 18.0 \\
93.7 \pm 18.9 \\
88.9 \pm 13.6 \\
99.5 \pm 0.8 \\
33.5 \pm 8.2\end{array}$ & $\begin{array}{l}0.706 \\
0.663 \\
0.929 \\
0.679 \\
0.224 \\
0.766\end{array}$ \\
\hline $\begin{array}{l}\text { Peroperative 10. minute } \\
\mathrm{SAB} \\
\text { DAB } \\
\text { MAP } \\
\mathrm{HR} \\
\mathrm{SpO}_{2} \\
\mathrm{BIS}\end{array}$ & $\begin{array}{l}114.4 \pm 17.1 \\
71.1 \pm 17.4 \\
86.4 \pm 16.9 \\
81.9 \pm 14.0 \\
99.1 \pm 0.9 \\
36.1 \pm 8.9\end{array}$ & $\begin{array}{l}112.9 \pm 18.6 \\
70.7 \pm 19.7 \\
87.0 \pm 19.6 \\
80.9 \pm 19.5 \\
99.0 \pm 0.7 \\
34.3 \pm 6.2\end{array}$ & $\begin{array}{l}0.853 \\
0.935 \\
0.767 \\
0.953 \\
0.529 \\
0.445\end{array}$ \\
\hline $\begin{array}{l}\text { Peroperative 20. minute } \\
\mathrm{SAB} \\
\text { DAB } \\
\mathrm{MAP} \\
\mathrm{HR} \\
\mathrm{SpO}_{2} \\
\mathrm{BIS}\end{array}$ & $\begin{array}{l}117.8 \pm 18.8 \\
74.5 \pm 18.3 \\
90.0 \pm 17.5 \\
76.9 \pm 12.8 \\
99.1 \pm 0.8 \\
40.7 \pm 7.2\end{array}$ & $\begin{array}{l}117.8 \pm 19.1 \\
73.4 \pm 17.8 \\
93.1 \pm 19.4 \\
78.4 \pm 12.6 \\
99.0 \pm 0.7 \\
35.2 \pm 8.4\end{array}$ & $\begin{array}{l}0.773 \\
0.790 \\
0.554 \\
0.756 \\
0.918 \\
\mathbf{0 . 0 1 9}\end{array}$ \\
\hline $\begin{array}{l}\text { Peroperative 30. minute } \\
\mathrm{SAB} \\
\text { DAB } \\
\mathrm{MAP} \\
\mathrm{HR} \\
\mathrm{SpO}_{2} \\
\mathrm{BIS}\end{array}$ & $\begin{array}{l}130.3 \pm 20.4 \\
80.7 \pm 12.9 \\
97.0 \pm 14.3 \\
73.8 \pm 10.3 \\
99.2 \pm 0.8 \\
43.8 \pm 6.0\end{array}$ & $\begin{array}{l}122.9 \pm 19.2 \\
73.7 \pm 13.3 \\
94.7 \pm 15.6 \\
76.6 \pm 13.4 \\
99.2 \pm 0.6 \\
38.6 \pm 7.2\end{array}$ & $\begin{array}{l}0.164 \\
0.067 \\
0.336 \\
0.549 \\
0.974 \\
0.009^{*}\end{array}$ \\
\hline $\begin{array}{l}\text { Before extubation } \\
\mathrm{SAB} \\
\mathrm{DAB} \\
\mathrm{HR} \\
\mathrm{SpO}_{2} \\
\mathrm{BIS}\end{array}$ & $\begin{array}{l}127.9 \pm 16.8 \\
81.9 \pm 14.5 \\
75.6 \pm 12.3 \\
99.4 \pm 0.6 \\
47.5 \pm 9.3\end{array}$ & $\begin{array}{l}124.0 \pm 20.6 \\
72.4 \pm 14.9 \\
75.4 \pm 13.0 \\
99.3 \pm 0.6 \\
40.0 \pm 7.0\end{array}$ & $\begin{array}{l}0.399 \\
0.062 \\
0.801 \\
0.748 \\
\mathbf{0 . 0 0 1}^{\star}\end{array}$ \\
\hline
\end{tabular}

${ }^{*} p<0.001$ statistically highly significant

Table 3: Consumption of the anesthesia drug and time to first analgesic requirement.

\begin{tabular}{|c|c|c|c|}
\hline & Group I & Group C & $\mathrm{p}$ \\
\hline Sevoflurane consumption $\%^{1}$ & $8.5 \pm 3.1$ & $20.1 \pm 5.8$ & $0.006^{*}$ \\
\hline The time to first analgesic requirement ${ }^{1}$ (hours) & $19.4 \pm 3.1$ & $1.2 \pm 0.4$ & $0.001^{*}$ \\
\hline
\end{tabular}

${ }^{1}$ Mean \pm Standard Deviation (SD); $p<0.001$ statistically highly significant. 
Table 4: The comparison of VAS values between Group I, Group C.

\begin{tabular}{|l|l|l|l|}
\hline VAS & Group I & Group C & p \\
\hline VAS 1 minute $^{1}$ & $0.00 \pm 0.00$ & $3.06 \pm 1.50$ & $\mathbf{0 . 0 0}^{*}$ \\
\hline VAS $1^{\text {st }}$ hour $^{1}$ & $0.43 \pm 0.89$ & $5.76 \pm 1.79$ & $\mathbf{0 . 0 0}^{*}$ \\
\hline VAS $^{\text {nd }}$ hour $^{1}$ & $0.53 \pm 1.00$ & $3.50 \pm 1.83$ & $\mathbf{0 . 0 0}^{*}$ \\
\hline VAS $6^{\text {th }}$ hour $^{1}$ & $0.70 \pm 1.11$ & $4.96 \pm 1.69$ & $\mathbf{0 . 0 0}^{*}$ \\
\hline VAS $12^{\text {th }}$ hour $^{1}$ & $1.20 \pm 1.47$ & $4.86 \pm 1.67$ & $\mathbf{0 . 0 0}^{*}$ \\
\hline
\end{tabular}

${ }^{1}$ Mean \pm Standard Deviation (SD); ${ }^{p} p<0.001$ statistically highly significant.

VAS: Visual analog pain scale

To reduce postoperative opioid consumption, analgesic and/or anti-inflammatory drugs and opioids are used before and during surgery. Among these drugs most commonly paracetamol and ibuprofen with low potential for side effects are used [8].

In a study evaluating the effect of ibuprofen on postoperative pain, $800 \mathrm{mg}$ ibuprofen was found to reduce postoperative opioid consumption [18]. In another study, preemptive analgesia together with postoperative primary care analgesic treatment has been shown to reduce opioid use more effectively [19].

Gazal, et al. found lower VAS scores in their group given ibuprofen and attributed this to anti-inflammatory activity of the drug [20]. Moss, et al. showed that single dose i.v. ibuprofen significantly reduced opioid consumption in the postoperative period in children undergoing tonsillectomy [21]. In our study, VAS scores, postoperative analgesic need together with the time to first analgesic need of the group who were given preemptive i.v. ibuprofen were comparatively lower.

Southworth, et al. stated that ibuprofen is a good option because of its analgesia and balanced anti-inflammatory effect [22]. In another study, it was reported that preoperative i.v. ibuprofen reduces stress response in laparoscopic cholecystectomies [23].

In their meta-analysis Moore, et al. emphasized that ibuprofen had a stronger analgesic effect compared to ibuprofen and paracetamol. However, in their study, oral forms of drugs were used [24]. The i.v. form of ibuprofen has been evaluated in different studies as for postoperative pain management.

In a study evaluating the effectiveness of i.v. ibuprofen and paracetamol for postoperative pain management in laparoscopic cholecystectomies, $800 \mathrm{mg}$ i.v. ibuprofen has been shown to result in lower pain scores and opioid consumption [25]. It has been reported that i.v. ibuprofen is very safe and effective in patients who will undergo orthopedic surgery [26].

In our study, we used a single dose of i.v. ibuprofen 15 minutes before anesthesia induction. Our aim was to reach peak plasma concentration at the beginning of the surgical stimulus and to see fewer side effects with a single dose of $400 \mathrm{mg}$.
There are some limitations for this study. First, ibuprofen $400 \mathrm{mg}$ was used as a single dose regardless of patients' weight. Different results and a different side effect profiles may have been obtained with a dose of $800 \mathrm{mg}$. The second limitation is that the $400 \mathrm{mg}$ dose was used only before surgery and not after surgery. We aimed to evaluate the effectiveness of the preemptive dose. Third, the effect on the length of hospital stay has not been evaluated.

In conclusion, preemptive single dose i.v. ibuprofen $(400 \mathrm{mg})$ reduced analgesic consumption in the first 24 hours postoperatively in patients undergoing laparoscopic cholecystectomy. Preemptive single dose of ibuprofen $(400 \mathrm{mg}$ ) can be used in laparoscopic cholecystectomy with the advantages of reducing the consumption of peroperative sevoflurane, providing better VAS scores, shortening the time to the first postoperative analgesic requirement and reducing analgesic consumption.

\section{References}

1. Protic M, Veljkovic R, Bilchik AJ, Popovic A, Kresoja M, et al. (2017) Prospective randomized controlled trial comparing standard analgesia with combined intra-operative cystic plate and port-site local anesthesia for post-operative pain management in elective laparoscopic cholecystectomy. Surg Endosc 31: 704-713.

2. Amornyotin S (2019) Anesthetic Management for Laparoscopic Cholecystectomy.

3. Kaufman E, Epstein JB, Gorsky M, Jackson DL, Kadari A (2005) Preemptive analgesia and local anesthesia as a supplement to general anesthesia: A review. Anesth Prog 52: 29-38.

4. Kissin I (2000) Preemptive analgesia. Anesthesiology 93: 1138-1143.

5. Gupta A, Bah M (2016) NSAIDs in the Treatment of Postoperative Pain. Curr Pain Headache Rep 20: 62.

6. (2012) Practice guidelines for acute pain management in the perioperative setting: An updated report by the american society of anesthesiologists task force on acute pain management. Anesthesiology 116: 248-273.

7. Rao P, Knaus EE (2008) Evolution of nonsteroidal anti-inflammatory drugs (NSAIDs): Cyclooxygenase (COX) inhibition and beyond. J Pharm Pharm Sci 11: S81-S110.

8. Koh W, Nguyen KP, Jahr JS (2015) Intravenous non-opioid analgesia for peri-and postoperative pain management: $A$ scientific review of intravenous acetaminophen and ibuprofen. Korean J Anesthesiol 68: 3-12. 
9. Gulay Erdogan Kayhana, Mukadder Sanlib, Ulku Ozgula, Ramazan Kirtekeb, Saim Yologluc (2018) Comparison of intravenous ibuprofen and acetaminophen for postoperative multimodal pain management in bariatric surgery: A randomized controlled trial. J Clin Anesth 50: 5-11.

10. De Peter KC, Blumberg SM, Dienstag Becker S, Meltzer JA (2017) Does the use of ibuprofen in children with extremity fractures increase their risk for bone healing complications? J Emerg Med 52: 426-432.

11. Gago Martínez A, Escontrela Rodriguez B, Planas Roca A, Martínez Ruiz A (2016) Intravenous Ibuprofen for Treatment of Post-Operative Pain: A Multicenter, Double Blind, Placebo-Controlled, Randomized Clinical Trial. PLoS One 11: e0154004.

12. Peter B Kroll, Laura Meadows, Amy Rock, Leo Pavliv (2011) A Multicenter, Randomized, Double-Blind, Placebo-Controlled Trial of Intravenous Ibuprofen (IV-Ibuprofen) in the Management of Postoperative Pain Following Abdominal Hysterectomy. Pain Pract 11: 23-32.

13. Hannah Zhao-Fleming, Audrey Hand, Kelly Zhang, Robert Polak, Armand Northcut, et al. (2018) Effect of non-steroidal anti-inflammatory drugs on post-surgical complications against the backdrop of the opioid crisis. Burn Trauma 6: 25.

14. Ahiskalioglu EO, Ahiskalioglu A, Aydin P, Yayik AM, Temiz A (2017) Effects of single-dose preemptive intravenous ibuprofen on postoperative opioid consumption and acute pain after laparoscopic cholecystectomy. Medicine 96: e6200.

15. Karim Saadati, Mohammad Reza Razavi, Daryoush Nazemi Salman, Shahrzad Izadi (2016) Postoperative pain relief after laparoscopic cholecystectomy: Intraperitoneal sodium bicarbonate versus normal saline. Gastroenterol Hepatol Bed Bench 9: 189-196.

16. Kelly DJ, Ahmad M, Brull SJ (2001) Preemptive analgesia I: Physiological pathways and pharmacological modalities. Can J Anaesth 48: 1000-1010.

17. Argyro Fassoulaki, Konstantinos Patris, Costantine Sarantopoulos, Quinn Hogan (2002) The analgesic effect of gabapentin and mexiletine after breast surgery for cancer. Anesth Analg 95: 985-991.

18. Southworth S, Peters J, Rock A, Pavliv L (2009) A multicenter, randomized, double-blind, placebo-controlled trial of intravenous ibuprofen 400 and $800 \mathrm{mg}$ every 6 hours in the management of postoperative pain. Clin Ther 31: 19221935.

19. Atkinson HC, Stanescu I, Frampton C, Salem II, Beasley CP, et al. (2015) Pharmacokinetics and bioavailability of a fixed-dose combination of ibuprofen and paracetamol after intravenous and oral administration. Clin Drug Investig 35: 625-632.

20. Gazal G, Al-Samadani KH (2017) Comparison of paracetamol, ibuprofen, and diclofenac potassium for pain relief following dental extractions and deep cavity preparations. Saudi Med J 38: 284-291.

21. Moss JR, Watcha MF, Bendel LP, McCarthy DL, Witham SL, et al. (2014) A multicenter, randomized, double-blind placebo-controlled, single dose trial of the safety and efficacy of intravenous ibuprofen for treatment of pain in pediatric patients undergoing tonsillectomy. Paediatr Anaesth 24: 483-489.

22. Southworth SR, Woodward EJ, Peng A, Rock AD (2015) An integrated safety analysis of intravenous ibuprofen (Caldolor((R)) in adults. J Pain Res 8: 753-765.

23. Vanny Le, Lakshmi Kurnutala, Joseph Schianodi Cola, Khaja Ahmed, Joel Yarmush, et al. (2016) Premedication with intravenous ibuprofen improves recovery characteristics and stress response in adults undergoing laparoscopic cholecystectomy: A randomized controlled trial. Pain Med 17: 1163-1173.

24. RA Moore, S Derry, PJ Wiffen, S Straube, DJ Aldington (2015) Overview review: Comparative efficacy of oral ibuprofen and paracetamol (acetaminophen) across acute and chronic pain conditions. Eur J Pain 19: 1213-1223.

25. Ekinci M, Çiftci B, Çelik EC, Köse EA, Karakaya MA, et al. (2020) A randomized, Placebo-controlled, double-blind study that evaluates efficacy of intravenous ibuprofen and acetaminophen for postoperative pain treatment following laparoscopic cholecystectomy surgery. J Gastrointest Surg 24: 780-785

26. Singla N, Rock A, Pavliv L (2010) A multicenter, randomized, double blind placebo controlled trial of intravenous ibuprofen (IV ibuprofen) for treatment of pain in postoperative orthopedic adult patients. Pain Med 11: 1284-1293. 